\section{(2) OPEN ACCESS}

\title{
Eggs, sugar, grated bones: colour-based food preferences in autism, eating disorders, and beyond
}

\author{
Mattias Strand (i) 1,2
}

${ }^{1}$ Stockholm Centre for Eating Disorders, Stockholm, Sweden ${ }^{2}$ Centre for Psychiatry Research, Department of Clinical Neuroscience, Karolinska Institutet, Stockholm, Sweden

\section{Correspondence to} Dr Mattias Strand, Stockholm Centre for Eating Disorders, Wollmar Yxkullsgatan 27B, 118 50 Stockholm, Sweden; mattias.strand@ki.se

Accepted 18 February 2020 Published Online First 27 April 2020

\section{ABSTRACT}

In 1913, eccentric French composer Erik Satie wrote a fragmentary, diary-like essay where he depicted a strikingly rigid diet consisting solely of white foods: eggs, sugar, coconuts, rice, cream cheese, fuchsia juice and so on. Satie's brief essay has later been used as one of many puzzle pieces in attempts to retrospectively diagnose him with autism spectrum disorder. With Satie's white meal as a starting point, this paper explores colour-based food preferences and selective eating in clinical and non-clinical populations, with a special focus on autism spectrum disorder and avoidant/restrictive food intake disorder (ARFID). General colour preferences and their causes as well as the impact of colour on taste and food identification are also explored. Selective eating during childhood is immensely common and does not generally lead to disordered eating in the long run, although subgroups may experience rigidity around food of a more enduring nature. Problems related to eating were repeatedly described in Kanner's original 1943 autism case series and continue to be common in autism. Most studies on eating and sensory sensitivity in autism show that the texture and consistency of the food are the most common factors behind selective eating. In contrast, colour-based food preferences appear to be relatively rare, although numerous anecdotal reports exist. Foods that are white or colourless may be particularly appealing or tolerable for individuals with sensory hypersensitivity, which can occur in autism or ARFID. Ultimately, in the case of Erik Satie, this paper concludes that his description of a strictly white diet should not be read as an autobiographical account but rather as an ironic take on contemporary symbolist literature, with the famously decadent all-black dinner party in French novelist Joris-Karl Huysmans' À Rebours (1884; also known as Against Nature) as an obvious source of inspiration.

\section{INTRODUCTION:'I EAT ONLY WHITE VICTUALS'}

In 1913, a fragmentary essay titled 'The Musician's Day', authored by French composer Erik Satie (1866-1925), was published in the periodical $\mathrm{La}$ Revue Musicale. Satie writes:

I eat only white victuals: eggs, sugar, grated bones; the fat of dead animals; veal, salt, coconuts, chicken cooked in white water; fruit mould, rice, turnips; camphorised sausage, pasta, cheese (cream), cotton salad and certain kinds of fish (without the skin). I have my wine boiled, and drink it cold with fuchsia juice. I am a hearty eater; but never speak while eating, for fear of strangling. ${ }^{1}$

Satie's eccentricity is well documented. In the tiny chaotic apartment in the south suburbs of Paris where he lived alone for several decades, he had managed to pile one grand piano on top of a second one and also stored large collections of assorted umbrellas and handkerchiefs. He once purchased seven identical velvet suits that he wore exclusively over the next 7 years. His musical scores include performer instructions such as 'Out of the corner of your hand' or 'Behave yourself, please: a monkey is watching you'. 'Satie's piano piece 'Vexations', which consists of the same 1 min musical phrase repeated 840 times over a duration of between 14 and 15 hours, foreshadows the mid-to-late 20th century endeavours in conceptual music. He took a deep interest in rare sea creatures, attempted to start his own religion as some sort of elaborate prank, and as he grew older he came to present himself as somewhat of a 'nutty professor figure': 'He seems to have felt uncomfortable being serious in public, the more so as the public warmed to him. His eccentricity became a disguise, an armour of winking and raillerie concealing a man nobody knew'. ${ }^{3}$

Retrospective diagnostics of famous historical figures could be described as a literary genre of its own. Saint Catherine of Sienna may ${ }^{4}$ or may not ${ }^{5}$ have suffered from anorexia nervosa in the 14th century; Lord Byron's volcanic eruptions of creativity may possibly have been an effect of bipolar disorder; ${ }^{6}$ the many quirks of inventor Nikola Tesla-necessarily walking around a block three times before entering a building, always staying in a hotel room with a number divisible by three, and so on-could very well be symptoms of obsessive-compulsive disorder. ${ }^{7}$ And indeed, Satie's eccentric aura has been described as the mark of an individual on the autistic spectrum. Here, a multitude of character traits-the composer's perfectionist handwriting, his strive for musical austerity and rejection of ornamentation, his great privacy, his interest in boredom (arguably instrumental in his invention of 'muzak'), his documented explosive temperament, and even his intricate sense of humour and reputation as a jester-has been invoked in order to demonstrate how a modern-day psychiatrist may have seen it fit to diagnose Satie with Asperger's syndrome. ${ }^{8}$ Not least, Satie's specific preference for the colour white, exhibited as part of his quest for purity as well as in his account of a diet consisting of 'coconuts, chicken cooked in white water; fruit mould, rice, turnips', has been seen as a hallmark feature of autism.

With Satie's white meal as a starting point, this narrative review explores colour-based food preferences and selective eating in clinical and nonclinical populations, with a special focus on autism spectrum disorder and eating disorders. General colour preferences and their potential causes as well as the impact of colour on taste and food identification are also explored. There is extensive 
literature on crossmodal sensory perception and appetite from the viewpoint of experimental psychology and marketing. Likewise, much clinical research has been performed on food preferences in autism and certain eating disorders as well as in neurotypically developing children with 'picky eating'. There is also the emerging discipline of 'neurogastronomy': the study of the complex neural processes behind our experiences of flavours during a meal. ${ }^{9}$ A comprehensive review of these bodies of literature are beyond the scope of this article. However, it appears as though the different research fields only rarely overlap and that they are seldom treated in an integrative fashion. Not least, as a clinician working primarily with patients with eating disorders, one is easily struck by the relative lack of attention to the everyday sensory aspects of food, cooking and eating in the clinical research literature. The aim of this paper is to address this gap and to attempt to bring the different perspectives on sensorybased food preferences together. Needless to say, many have pointed to the absolute necessity of understanding psychiatric conditions in their social and cultural contexts. ${ }^{10}$ Arguably, few 'medical' phenomena are as intertwined with our lives as cultural creatures as those disorders that involve disruptions surrounding food and eating, ${ }^{11}$ underscoring the relevance of approaching them from the interdisciplinary perspective of medical humanities. Notably, many clinical reports on rigid colour preferences are of a highly anecdotal nature; thus, the associations with the literary 'case study' of Satie can hopefully serve as a starting point for a broader discussion about the nature and implications of this phenomenon.

This article is not about synaesthesia-nevertheless, it is worth briefly mentioning this related phenomenon, since many people are probably familiar with synaesthetic symbolist painters and composers of the same era as Satie. Synaesthesia is a neurological trait that gives rise to cross-sensory experiences, such as 'seeing' colours when listening to music or associating different tastes with specific shapes. ${ }^{12}$ The most common form is probably the so-called grapheme-colour synaesthesia, in which letters and numbers are experienced as colourful; for example, philosopher Ludwig Wittgenstein would describe how for him, 'the vowel e is yellow'. ${ }^{13}$ The late 19th century has indeed been called the 'golden age of synaesthesia inquiry, ${ }^{14}$ as both neurologists and artists of the time took a great interest in the phenomenon. Not seldom, fin-de-siècle symbolist artists sought to create pieces of 'omni-art' whereby many senses would be called on simultaneously. Hallmark examples are composer Alexander Scriabin's use of colour organs or his search for the 'unification of music, coloured lights, mist, incense, fragrance, drama, poetry, dance [...] performed against the backdrop of the Himalayas'. ${ }^{15}$ It has been questioned if Scriabin was a 'true' synaesthete or if he merely made the artistic choice to explore the synaesthetic universe in his compositions; nevertheless, he and many of his contemporary symbolists certainly described themselves as 'real' synaesthetes. ${ }^{16}$

\section{Patient and public involvement}

This article has been inspired by seeing numerous patients with disordered eating due to sensory sensitivity who have often expressed that they cannot fully relate to the standard treatments offered in specialist eating disorder services, which are often specifically designed for 'typical' eating disorders such as anorexia nervosa, bulimia nervosa or binge eating disorder. However, due to the theoretical nature of the study, the research was done without patient involvement. Patients were not invited to comment on the outline of the study and were not consulted to develop patient relevant perspectives. Patients were not invited to contribute to the writing or editing of this article for readability or accuracy.

\section{AUTISM AND SENSORY SENSITIVITY}

Colour preferences are seldom mentioned in relation to mental illness; when food colour is discussed in conjunction with psychiatry, it is usually in reference to the potential relationship between artificial food colouring and symptoms of attentiondeficit/hyperactivity disorder ${ }^{17}$ or other negative health consequences. ${ }^{18}$ Although numerous anecdotal reports of rigid colour-based food preferences exist-for example, a mother of two boys with autism has described how one of her sons would use ketchup to mask unwelcome colours, since he would only eat red foods ${ }^{19}$ - there is relatively little research evidence on this specific phenomenon. Selective or 'picky' eating in a broader sense, as well as food neophobia (that is, the unwillingness to try new and unknown foods), is of course tremendously common among children. Most children display a reduced appetite and a decrease in growth rate between 2 years and 6 years of age as a feature of normal development. ${ }^{20}$ In a prospective study of 120 children in San Francisco, 13\%-22\% were reported to be selective eaters at any given age between 2 years and 11 years and $39 \%$ of the cohort were selective eaters at some point. ${ }^{21}$ Similarly, in a study of 426 German junior school children, 19\% of the girls and $18 \%$ of the boys displayed selective eatingthese children ate a more limited number of foods, more often required special preparation of meals, and their parents reported more struggles around food in the family as well as more worries about their children's health. ${ }^{22}$ However, even though selective eating during childhood can certainly give rise to family conflict and turn restaurant visits and dinner parties into veritable obstacle courses, in a large majority of cases the child's weight is, in fact, not negatively affected. ${ }^{23}$ Likewise, selective eating during childhood does not generally lead to eating disorders in the long run, ${ }^{24}$ although subgroups may experience rigidity around food of a more enduring nature. ${ }^{25}$

One such subgroup appears to be individuals with autism. Although not a definitive criterion in the current diagnostic classification systems, problems related to eating were repeatedly described in Leo Kanner's original 1943 autism case series. Here, Kanner notes that ' $[\mathrm{f}]$ ood is the earliest intrusion that is brought to the child from the outside', an intrusion that can become overwhelming for children with autism. ${ }^{26}$ Most of the research on the nature of selective eating has, in fact, been performed with samples of individuals with autism spectrum disorder. A number of retrospective studies have reported low breastfeeding rates and early weaning in children who are later diagnosed with autism; this has often been interpreted as evidence for viewing breastfeeding as a protective factor, but could just as well point to feeding difficulties as an integral part of the disorder itself. ${ }^{27} \mathrm{~A}$ meta-analysis of research on food intake among children with autism found a fivefold increase in the odds of having a feeding problem in this population, selective eating being the most common obstacle. ${ }^{28}$ In a study comparing 53 children with autism with 58 typically developing children, the autism group was significantly more likely to refuse food based on texture and consistency $(77.4 \%$ vs $36.2 \%)$, taste and smell (49.1\% vs $5.1 \%)$, ingredients being served in a mixture $(45.3 \%$ vs $25.9 \%)$, brand (15.1\% vs $1.7 \%)$ and shape $(11.3 \%$ vs $1.7 \%) .{ }^{29}$ In contrast, no differences were seen for food refusal based on temperature (30.2\% vs $24.1 \%$ ), foods touching other foods on the plate $(20.8 \%$ vs $17.2 \%)$ or colour (15.1\% vs $12.1 \%)$. Similar studies have repeatedly 
identified colour-based food selectivity as a real but relatively rare phenomenon ${ }^{30}$-time and again, texture is found to be the most common factor in food refusal. In general, children with autism tend to prefer crispy or crunchy food ${ }^{31}$ as well as salty and savoury dishes, ${ }^{32}$ but they may also be more likely to only accept foods of low texture, such as puréed foods. ${ }^{33}$ To parents' chagrin, these children often become experts in detecting when unwanted food item is 'hidden' in other foods. ${ }^{34}$ Findings on selectivity based on food colour are, however, mostly anecdotal: one child will reportedly only eat red apples, another child refuses all vegetables that are not white, ${ }^{35}$ and so on.

This increased prevalence of food-related problems seems to extend to non-clinical populations with autistic traits as well. ${ }^{36}$ The reasons behind the observed sensory selectivity in individuals on the autistic spectrum are not fully known. A paradoxical simultaneous hyposensitivity and hypersensitivity to sensory stimuli has been noted in autism. Respondents may, for example, report being extremely sensitive to high-pitched noises or the buzzing of a fridge, while also requiring unusually powerful taste stimuli in order to experience food as appetising. ${ }^{37} \mathrm{~A}$ tendency to become overwhelmed by sensory stimuli is also common in autism, as well as strong preferences for certain stimuli qualities or sameness in stimuli. When it comes to general colour preferences, it has been hypothesised that an increased sensory sensitivity in autism results in aversion to specific colours. A comparison between neurotypical children and children on the autistic spectrum showed that while both groups liked the colours red and blue, the typically developing children also liked yellow and disliked brown, whereas the children with autism tended to avoid yellow and instead favoured brown and green. ${ }^{38} \mathrm{~A}$ possible explanation behind these findings is that in terms of retinal photoreceptor dynamics, yellow is the most fatiguing colour and may therefore become unbearably stimulating for children with autism. A number of visual function impairments have also been demonstrated in autism; among these, a generally poor colour detection capacity, rather than any specific colour defect (such as blue-yellow or red-green colour blindness), has been observed. ${ }^{39}$ But again, as noted above, sensory selectivity based on food colour specifically appears to be relatively rare even in groups with an overall inclination towards selective eating, such as individuals with autism. As described in more detail below, general colour preferences may also be distinctly different from food colour preferences in autism as well as in the population at large.

It should be noted that texture, rather than colour or other food properties, is generally also the most important sensory aspect behind food rejection in non-autistic, non-clinical populations: ${ }^{40}$

\footnotetext{
When customers complain about products available in a grocery store or at the market or when diners in a restaurant express dissatisfaction with a dish, it can almost always be traced back to mouthfeel. We seldom complain that something tastes bad. Instead we might say that the souffle has collapsed, the meat is too tough, the French fries have gone soggy, the bread is dry, the coffee is tepid, the mustard lacks bite, and so on. [...] It is much easier to describe an unfulfilled expectation related to texture than one that concerns chemical sensations, such as taste and aroma. ${ }^{41}$
}

In particular, the most frequently used word to describe positive connotations regarding texture, at least in Europe and the USA, is 'crisp'; ${ }^{42}$ as seen above, this holds true in autism as well. ${ }^{43}$ In contrast, autistic treats or not, Satie's white diet is hardly characterised by crispness. Rice, eggs and 'the fat of dead animals' are certainly not the kind of foods that are usually associated with a crunchy texture and they are highly unlikely to appeal to the typical individual with rigid texture-based food preferences.

\section{THE BOY WITH THE BLUE-TINTED GLASSES}

In a fascinating case report, Amanda Ludlow and colleagues describe a young boy, referred to as J.G., with autism spectrum disorder and strong reactions to multiple types of sensory inputs, including colour obsession and phobias. ${ }^{44}$ In particular, J.G. has a marked preference for blue and purple, combined with an aversion to bright colours. His family has attempted to adjust his home environment according to these preferences in order to reduce stress: J.G.'s bedroom is painted purple, his clothes are all dark blue, and the family drives a blue car with purple interior. Reportedly, J.G. once even attempted to paint the family dog blue. This colour obsession also impacts on his eating. Since blue or purple foods are highly unusual, J.G. opts for white food items and cannot tolerate more than two colours at once on his plate. Thus, between ages 1 and 9 years, most of his meals were served between two slices of bread. ${ }^{45}$ J.G. reports painful sensations in his eyes as well as nausea when exposed to bright colours-consequently, he wears sunglasses at all times, even indoors. On a chromatic discrimination task, perhaps somewhat surprisingly, J.G. displayed a pattern of selective deficit in the very colour region that he prefers, indicating that his attraction to blue and purple may be due to a hyporeactivity to these colours, thus avoiding sensory overload. Interestingly, in a follow-up report the authors describe how J.G. had subsequently received blue-tinted glasses, which significantly reduced his adverse reactions to aversive colour stimuli and enabled him to partake in everyday activities. ${ }^{46}$ It can be noted that blue-tinted spectacles are sometimes prescribed as a remedy for the 'visual stress' associated with the Mearles-Irlen syndrome, ${ }^{47}$ a proposed and somewhat controversial diagnosis involving visual distortions as well as (perhaps) learning disabilities and dyslexia. ${ }^{48}$ Furthermore, blue-tinted glasses have actually been marketed as a dieting aid by a Japanese company ${ }^{49}$ - supposedly, they act as an appetite suppressant precisely due to the scarcity of naturally blue foods. 50

Another psychiatric condition that may involve selective, colour-based eating is the so-called avoidant/restrictive food intake disorder, usually abbreviated as ARFID, that was introduced as a new diagnosis in the eating and feeding disorders chapter of the fifth edition of the Diagnostic and Statistical Manual of Mental Illness in 2013. ${ }^{51}$ ARFID is explicitly an umbrella term, used to cover several types of restrictive eating with the common denominator that they do not occur in a context of body image concerns or a wish for thinness, as in anorexia nervosa or bulimia nervosa. Emerging evidence exists for the subdivision of ARFID into three clinical dimensions: low homeostatic appetite, fear of aversive consequences such as choking or vomiting, and sensory sensitivity of the kind described above. ${ }^{52}$ These presentations are not mutually exclusive. It has been noted that the symptoms of an individual with ARFID can often be plotted along all of these three dimensions; a typical case could, for example, involve a history of chronic low appetite and 'picky eating' during childhood which is later acutely exacerbated after a traumatic event, such as choking on a piece of food. ${ }^{53}$ Interestingly, there is often a potentially confusing comorbidity between ARFID and autism spectrum disorder; here, the ARFID diagnostic criteria specify that if the restrictive eating is part of broader mental health issues, the ARFID diagnosis should only be used when the severity of the eating problems exceeds that which is commonly seen and warrants additional clinical attention. ${ }^{54}$

\section{WHAT COLOURS DO PEOPLE LIKE, AND WHY?}

Certainly, colour-based food preferences are not a unique feature of individuals with autism spectrum disorder or ARFID-far from 
it. In fact, the colour aspect of food and drinks is vital for our experience of flavour and can, if slightly off, act as an effective appetite killer. In an oft-cited 1970s study, ${ }^{55}$ dinner guests were served steak, chips and peas in a dimly lit environment specially designed so as to show the food on the plates but not its colour. When the lights were turned on fully halfway through the meal, it was revealed that the peas had been coloured red, the chips lime green, and the steak a vibrant blue. Reportedly, at the sight of the artificially coloured food, several dinner guests immediately fell sick and headed straight for the bathroom. There is a well-documented general aversion to blue food, which is especially striking given that blue is often rated as the most preferred colour in non-food contexts. ${ }^{56}$ This could be a result of there not being very many naturally blue food items, so that the colour blue in food has come to be associated with unappealing artificiality; alternatively, human evolution may have made us implicitly associate blue food with mould and risk of poisoning. Culinary experiments with sushi dipped in blue food dye, ${ }^{57}$ neon purple udon noodles served with blue tofu, ${ }^{58}$ or glow-in-the-dark ramen ${ }^{59}$ are fascinating as expeditions into the overlapping territories of cooking, art and sciencenevertheless, in the case of blue sushi, none of the participants even dared to try it. ${ }^{60}$

Scholarly interest in the psychological aspects of colours can be traced back to German writer Johan Wolfgang von Goethe and his work Zur Farbenlehre (or Theory of Colours), which was published in 1810. In a wide-ranging exposé, Goethe here attempted to unravel the perceptual essentials of colours and their 'sensory-moral' effects, ${ }^{61}$ symbolically associating red and crimson with the beautiful, yellow with the good, green with the useful, and so on. Goethe's ideas were later integrated with clinical observations by German neurologist and psychiatrist Kurt Goldstein, who suggested that the colours green and blue have a relaxing, stabilising and introspective effect, whereas red and yellow are stimulating and prompt an outward focus. ${ }^{62}$ Interestingly, in line with Goldstein's theory, studies on the psychophysiological effects of coloured medicine tablets and capsules show that red, yellow and orange drug formulations tend to be perceived as stimulant, in contrast to green, purple and blue which are seen as tranquillising and are, consequently, more often used for sedative and anxiolytic drugs. ${ }^{63}$

In experimental research on colour preferences, people systematically prefer cool colours such as blue, purple or green over warm colours-blue tends to be the most preferred colour whereas yellow and yellow-green are least favoured. ${ }^{64}$ Higher saturation and increasing lightness, at least to a certain point, is also usually preferred. However, different colours are preferred at different levels of lightness. In particular, dark yellow and orange-olive and brown, that is-are much disliked relative to lighter tones of the same hues. As noted above, there may be evolutionary components at play behind these tendencies. It has been suggested that cyan and green are generally attractive because they elicit positive affects through their association with clean water, clear skies and lush foliage, whereas various shades of brown are implicitly coupled to faeces and decaying food that is best left untouched. ${ }^{65}$ Even so, for some reason, people are obviously capable of harbouring a strong affection for such brown food items as chocolate or coffee. As we have seen, colour preferences are highly contextual: even individuals with a love for the colour blue usually like their bananas yellow. ${ }^{66}$

\section{DECEIVING OUR TASTE BUDS}

Not least, food colour helps us in identifying what it is we are eating. There is an extensive experimental research literature on the impact of food colour on taste identification and intensity and a full review is beyond the scope of this article (see instead, for example, Spence 2015). Nevertheless, a few illustrative examples are useful to contextualise the findings on sensory preferences in autism and ARFID. In a classic 1974 study, flavour chemist Joseph Maga demonstrated how adding tasteless red, green or yellow food colouring to clear water solutions altered the threshold sensitivity for the basic tastes sweet, sour and bitter. ${ }^{67}$ For example, after adding green colouring to a sucrose-water solution, participants described it as sweet at a lower sucrose concentration than before. In contrast, adding yellow or red colouring made the sweet solution more difficult to detect. In the case of sourness, both green and yellow colouring decreased sensitivity, and red colouring made it more difficult to detect bitterness. Notably, participants' detection threshold for saltiness was not altered by adding food colouring, perhaps because various foods of different colours (potato chips, popcorn, olives, pickles and so on) are associated with a salty taste. Later studies, however, have demonstrated that people do tend to associate saltiness with the colour white. ${ }^{68}$

In the same vein, a study by wine scientist Wendy Parr and colleagues investigated olfactory perceptual bias in casual wine drinkers as well as in wine connoisseurs and demonstrated that both groups tended to describe odours typical to red wines (cherry, plum, black pepper and so on) when tasting white wine that had been coloured red. ${ }^{69}$ This study has recently been replicated and extended, demonstrating how the pink hue of rosé wine similarly influences the perceived flavour and aroma in wine novices a well as in experts. ${ }^{70}$ Context is also important: a blue-coloured drink in a plastic cup may be expected to taste of mint-as in mouthwash-whereas the same drink presented in a cocktail glass may instead signify the orange flavour of blue curaçao. ${ }^{71}$ In general, people tend to expect more intensely coloured food to have a more intense taste; however, at a certain point, vivid colours may lead consumers to associate food with artificiality and therefore like it less. ${ }^{72}$ Furthermore, there are cross-cultural differences in common connotations between colour and taste. In a study comprising 452 participants from China, India, Malaysia and the USA it was found that individuals from all four countries associated black colour with bitterness, white with saltiness, green with sourness and pink with sweetness. ${ }^{73}$ However, Chinese participants tended to associate purple with sourness, whereas Malaysian participants thought of green as distinctly sour. Interestingly, the US participants more often thought of blue as sweet-perhaps due to a culture-specific association between the colour blue and raspberry flavoured soft drinks, which, in turn, can be traced back to a more or less haphazard use of novel artificial food colouring in the early 1970s. ${ }^{74}$

In contrast, foods that are served in a colourless clear or white form usually do not taste very much at all. ${ }^{75}$ This may very well be a sought-after characteristic in certain contexts. As noted above, for lack of blue and purple foods, autistic boy J.G. preferred to have his meals served between slices of white bread. Likewise, a case report describing a 42-year-old man with ARFID reports how the patient displays a clear preference for 'plain foods', such as white bread sandwiches. ${ }^{76}$ In their manual for cognitive-behavioural therapy in ARFID, ${ }^{77}$ therapists Jennifer Thomas and Kamryn Eddy note that individuals with ARFID characterised by sensory sensitivity often follow a 'white diet, consisting, for example, of white-coloured dairy and grains (e.g., pasta with butter, vanilla ice cream, crackers, breakfast cereal) and few or no fruits, vegetables, or proteins'substitute camphorised sausage with spaghetti and ice cream and we have a 21st century version of Satie's diet. It may also be noted that, in contrast, contemporary promoters of 'healthism' have 
launched a 'nothing white' diet, ${ }^{78}$ focusing on a sharply reduced intake of refined carbohydrates, although the rationale behind this can be questioned. ${ }^{79}$

There have been anecdotal reports of celebrities with a special fondness for white foods-however, it is usually highly uncertain whether this is due to 'real' sensory sensitivity, an overall air of eccentricity or something else. Reportedly, fashion designer Yves Saint Laurent preferred his food white ${ }^{80}$ (although his favourite colours in other contexts were black and pink $^{81}$ ). Likewise, movie producer Leland Hayward is said to never have wanted anything but white foods, such as scrambled eggs, chicken, custard and vanilla ice cream. ${ }^{82}$ It has been suggested that the symbolic association between the colour white and purity, just as in the case of Satie ${ }^{83}$ might explain these artistic types' fondness for white foods. $^{84}$

Such an association between whiteness and purity need not only be symbolic. Historically, it can be noted that in the latter half of the 19th century, just around the time that Satie was born, big food manufacturers first started employing industrial chemists who were tasked with inventing 'new aids to deception-deodorants, dyes, flavours, crispers for flabby foods, and softeners for hard foods-which left consumers thoroughly confused about what they were eating, ${ }^{85}$ Population growth and increased urbanisation called for novel methods for the production of cheap and durable food, which included improving the looks of mass-produced food items with artificial food colouring. Public and government reactions to these developments were highly ambivalent. On the one hand, scientists of the time assured the public that the new inventions in food technology were beneficial and safe; this was indeed the era of burgeoning positivism and engineers were eager to provide rational solutions to the societal problems at hand. On the other hand, many people found the technological advancements intimidating. Concerns about the safety of the various artificial additives were raised and a new league of food 'purists' warned against insidious 'cheating' and 'adulteration'. 86 For example, German-born scientist Frederick Accum authored a much-debated book in which he uncovered how the rainbow colours of boiled sweets were produced by using poisonous copper salts and how the orange rind of Gloucester cheese was created with the help of red lead. ${ }^{87}$ Antiadulteration associations were founded and bills prohibiting the use of various artificial components were brought before the parliaments of Britain, the USA and other countries. One can imagine how a widespread suspicion against food chemists and deceitful grocers might have contributed in steering individuals with rigid food preferences towards an even more minimalistic diet-excluding, for example, colourful foods-around the turn of the 20th century.

\section{CONCLUSION: SATIE, HUYSMANS AND THE CULTURE OF BOREDOM}

So, does not Satie indeed qualify for an ARFID diagnosis- he who never spoke while eating, 'for fear of strangling'? Or are his mealtime preferences rather the hallmark of an individual with autism? Was he perhaps afraid of food adulteration? As it turns out, in the risky business of retrospective diagnostics, Satie's writing on chicken and fuchsia juice does not tell us much of anything about himself, simply because it is not autobiographical, as some have implied; ${ }^{88}$ parts of his white meal are virtually inedible anyway. ${ }^{89}$ Instead, 'The Musician's Day' should be read as an ironic take on contemporary literature. Readers may already have noticed that the white meal described by Satie is clearly inspired by yet another monochromatic meal in literature: the all-black dinner party thrown by the eccentric aristocrat
Des Esseintes in French novelist Joris-Karl Huysmans’ À Rebours (also known as Against Nature), published in 1884:

The dining room, draped in black, opened out onto a garden metamorphosed for the occasion, the paths being strewn with charcoal, the ornament pond edged with black basalt and filled with ink, and the shrubberies replanted with cypresses and pines. The dinner itself was served on a black cloth adorned with baskets of violets and scabious; candelabra shed an eerie green light over the table and tapers flickered in the chandeliers. [...] Dining off black-bordered plates, the company had enjoyed turtle soup, Russian rye bread, ripe olives from Turkey, caviare, mullet botargo, black puddings from Frankfurt, game served in sauces the colour of liquorice and boot-polish, truffle jellies, chocolate creams, plum-puddings, nectarines, pears in grapejuice syrup, mulberries and black heart-cherries. ${ }^{90}$

A number of aspects-the demoralising defeat in the FrancoPrussian war, undercurrents of philosophical pessimism inspired by Schopenhauer's writings and an increased interest in the occultinteracted in steering French as well as broader European culture away from rationalist positivism towards pessimist symbolism, spiritism and a medical obsession with neurological degeneration in the last few decades of the 19 th century. ${ }^{91}$ Huysmans can be seen as a portal figure of these tendencies. In $\grave{A}$ Rebours, a novel that has 'come to a near standstill', the main protagonist Des Esseintes is a hedonist Parisian dandy plagued by the ever-present 'sickness of the century' that afflicted so many of his contemporary young adults: disillusionment, rootlessness, crippling feelings of banality and a deep-seated sense that they had been born into 'a world which seemed not to need them'. ${ }^{92}$ In response, Des Esseintes withdraws to live alone in an isolated villa on the outskirts of the city where he spends his days indulging in exotic jewels and perfumes as well as in his own impotence and digestive problems. Here, Huysmans combines naturalist interest in the very concrete-reflected in Des Esseintes' meticulous attention to the details of refinement, such as in the famous description of the gem-encrusted shell of a living tortoise-with symbolist and decadent subjects of solitude, perversion and nausea. Indeed, these ingredients have over the years turned À Rebours into somewhat of a cult classic; the novel has also, however, been laconically dismissed as 'a book about interior decoration'. ${ }^{93}$

Huysmans' meticulous description of the black dinner party could be compared with modern-day 'food porn': sensual images of appealing dishes that are consumed visually on blogs or in glossy magazines rather than viscerally at the dining table. ${ }^{94}$ Surely, in this sense Satie's ironic diet is not simply a white version of Des Esseintes' spleen-drenched extravagance; there is nothing pornographic about the veal, salt and coconuts of his rigidly anaemic meal. Whereas Des Esseintes' dinner is pure decadence, that of Satie is austerity and mortification. It has been suggested that the liquorice and boot-polish dinner party conjured up by Huysmans is ' $a$ feast for the eyes rather than for the palate [...] served at the kind of party to which you want to be invited, but not the place to go if you're hungry'. ${ }^{95}$ Certainly, Satie's turnips and rice do not induce much of a party mood at all, but they are probably also unlikely to satisfy the hungry gourmand. If Satie's white meal-although hardly an autobiographical account-evokes the idea of an individual with selective eating and sensory sensitivity, perhaps against a backdrop of autism-like traits, Des Esseintes' black meal is that of exuberance, decadent artificiality and fin-de-siècle existential boredom. And, as Peter Toohey notes in his book Boredom: A Lively History, boredom 'is an emotion usually associated with a nourished body: like satiety, it is not normally for the starving. ${ }^{96}$ The spare, white meal described in 'The Musician's Day' is, in contrast, indicative 
of a need to indeed create something radically new in reaction to the prevailing self-indulgent pessimism of the time-after all, this is the author-composer who, as an ironic take on boredom, created 'muzak'. In retrospect, we can be certain that if anything, Erik Satie was not bored.

Contributors MS is the sole author of this article.

Funding The authors have not declared a specific grant for this research from any funding agency in the public, commercial or not-for-profit sectors.

Competing interests None declared.

Patient and public involvement Patients and/or the public were not involved in the design, conduct, reporting or dissemination plans of this research.

Patient consent for publication Not required.

Provenance and peer review Not commissioned; externally peer reviewed.

Data availability statement Data sharing not applicable as no data sets generated and/or analysed for this study.

Open access This is an open access article distributed in accordance with the Creative Commons Attribution Non Commercial (CC BY-NC 4.0) license, which permits others to distribute, remix, adapt, build upon this work non-commercially, and license their derivative works on different terms, provided the original work is properly cited, appropriate credit is given, any changes made indicated, and the use is non-commercial. See: http://creativecommons.org/licenses/by-nc/4.0/.

\section{ORCID iD}

Mattias Strand http://orcid.org/0000-0003-4799-0737

\section{NOTES}

1. Ornella Volta (1996), A Mammal's Notebook: The Writings of Erik Satie (London, UK: Atlas Press), p. 112

2. Volta, p. 51.

3. Nick Richardson (2015), "Velvet Gentleman. [Review of the Book A Mammal's Notebook: The Writings of Erik Satie.]," London Review of Books, 37(11): 26-28, p. 26.

4. Rudolph M Bell (1987), Holy Anorexia (Chicago, IL: University of Chicago Press).

5. Joan Jacobs Brumberg (1988), Fasting Girls: The Emergence of Anorexia Nervosa as a Modern Disease (Cambridge, MA: Harvard University Press).

6. Kay Redfield Jamison (1993), Touched with Fire: Manic-Depressive Illness and the Artistic Temperament (New York, NY: Free Press).

7. Richard Gunderman (2018), "The Extraordinary Life of Nikola Tesla," Smithsonian Magazine, https://www.smithsonianmag.com/innovation/extraordinary-life-nikolatesla-180967758/.

8. Catherine H M Fung (2009), "Asperger's and Musical Creativity: The Case of Erik Satie," Personality and Individual Differences, 46(8): 775-83.

9. Charles Spence and Betina Piqueras-Fiszman (2014), The Perfect Meal: The Multisensory Science of Food and Dining (Oxford, UK: Wiley Blackwell).

10. Laurence J Kirmayer, Robert Lemelson and Constance A Cummings (2015), ReVisioning Psychiatry: Cultural Phenomenology, Critical Neuroscience, and Global Mental Health (Cambridge, UK: Cambridge University Press).

11. Mervat Nasser, Melanie A Katzman, and Richard A Gordon (2001), Eating Disorders and Cultures in Transition (Hove, UK: Brunner-Routledge); Raymond Tallis (2008), Hunger (Stocksfield, UK: Acumen Publishing).

12. Caroline Curwen (2018), "Music-Colour Synaesthesia: Concept, Context and Qualia," Consciousness and Cognition, 61: 94-106.

13. Jamie Ward (2013), "Synesthesia," Annual Review of Psychology, 64(1): 49-75, p. 51.

14. Jörg Jewanski et al. (2019), "The 'Golden Age' of Synesthesia Inquiry in the Late Nineteenth Century (1876-1895)," Journal of the History of the Neurosciences, $1-28$.

15. Lazaros C Triarhou (2016), "Neuromusicology or Musiconeurology? 'Omni-Art' in Alexander Scriabin as a Fount of Ideas," Frontiers in Psychology, 7: 364, p. 3.

16. John Harrison (2001), Synaesthesia: The Strangest Thing (Oxford, UK: Oxford University Press).

17. L Eugene Arnold, Nicholas Lofthouse, and Elizabeth Hurt (2012), "Artificial Food Colors and Attention-Deficit/Hyperactivity Symptoms: Conclusions to Dye For," Neurotherapeutics, 9(3): 599-609.

18. Charles Spence (2016), "The Psychological Effects of Food Colors," in Handbook on Natural Pigments in Food and Beverages, ed. Reinhold Carle and Ralf M Schweiggert (Duxford, UK: Woodhead Publishing), 29-58.

19. Charlotte Moore (2004), George and Sam: Autism in the Family (London, UK: Viking Penguin).
20. Callie L Brown et al. (2016), "Association of Picky Eating and Food Neophobia with Weight: A Systematic Review," Childhood Obesity, 12(4): 247-62.

21. Anthony J Mascola, Susan W Bryson, and W Stewart Agras (2010), "Picky Eating during Childhood: A Longitudinal Study to Age 11 Years," Eating Behaviors, 11(4): 253-7.

22. Corinna Jacobi, Gabriele Schmitz, and W Stewart Agras (2008), "Is Picky Eating an Eating Disorder?," International Journal of Eating Disorders, 41(7): 626-34.

23. Brown et al.; Mascola, Bryson, and Agras; Jacobi, Schmitz, and Agras.

24. Jacobi, Schmitz, and Agras; Gertrud Sofie Hafstad, Tilmann von Soest, and Leila Torgersen (2013), "Early Childhood Precursors for Eating Problems in Adolescence: A 15-Year Longitudinal Community Study," Journal of Eating Disorders, 1(1): 35; L A Kotler et al. (2001), "Longitudinal Relationships Between Childhood, Adolescent, and Adult Eating Disorders," Journal of the American Academy of Child \& Adolescent Psychiatry, 40(12): 1434-40.

25. Mascola, Bryson, and Agras.

26. Leo Kanner (1943), "Autistic Disturbances of Affective Contact," Nervous Child, 217-50, p. 244

27. Sanne Lemcke et al. (2018), "Early Regulation in Children Who Are Later Diagnosed with Autism Spectrum Disorder. A Longitudinal Study within the Danish National Birth Cohort," Infant Mental Health Journal, 39(2): 170-82.

28. William G Sharp et al. (2013), "Feeding Problems and Nutrient Intake in Children with Autism Spectrum Disorders: A Meta-Analysis and Comprehensive Review of the Literature," Journal of Autism and Developmental Disorders, 43(9): 2159-73.

29. Kristie L Hubbard et al. (2014), "A Comparison of Food Refusal Related to Characteristics of Food in Children with Autism Spectrum Disorder and Typically Developing Children," Journal of the Academy of Nutrition and Dietetics, 114(12): 1981-87.

30. Kelli C Dominick et al. (2007), "Atypical Behaviors in Children with Autism and Children with a History of Language Impairment," Research in Developmental Disabilities, 28(2): 145-62; Cynthia R Johnson et al. (2008), "Eating Habits and Dietary Status in Young Children with Autism," Journal of Developmental and Physical Disabilities, 20(5): 437-48; Geneviève Nadon et al. (2011), "Mealtime Problems in Children with Autism Spectrum Disorder and Their Typically Developing Siblings: A Comparison Study," Autism, 15(1): 98-113.

31. Sharp et al.

32. Elizabeth. Cornish (1998), "A Balanced Approach Towards Healthy Eating in Autism," Journal of Human Nutrition and Dietetics, 11(6): 501-9.

33. Kimberly A Schreck, Keith Williams, and Angela F Smith (2004), "A Comparison of Eating Behaviors Between Children with and Without Autism," Journal of Autism and Developmental Disorders, 34(4): 433-8.

34. Cornish.

35. Cornish; Donna W Lockner, Terry K Crowe, and Betty J Skipper (2008), "Dietary Intake and Parents' Perception of Mealtime Behaviors in Preschool-Age Children with Autism Spectrum Disorder and in Typically Developing Children," Journal of the American Dietetic Association, 108(8): 1360-3.

36. Stephanie Stensbjerg Christensen et al. (2019), "Disordered Eating Behaviours and Autistic Traits—Are There Any Associations in Nonclinical Populations? A Systematic Review," European Eating Disorders Review, 27(1): 8-23.

37. Marie Elwin et al. (2013), "Too Much or Too Little: Hyper- and Hypo-Reactivity in HighFunctioning Autism Spectrum Conditions," Journal of Intellectual \& Developmental Disability, 38(3): 232-41.

38. Marine Grandgeorge and Nobuo Masataka (2016), "Atypical Color Preference in Children with Autism Spectrum Disorder," Frontiers in Psychology, 7: 1976.

39. Asmaa Bakroon and Vasudevan Lakshminarayanan (2016), "Visual Function in Autism Spectrum Disorders: A Critical Review," Clinical and Experimental Optometry, 99(4): 297-308.

40. John Prescott (2012), Taste Matters: Why We Like the Foods We Do (London, UK: Reaktion Books).

41. Ole G Mouritsen and Klavs Styrbæk (2017), Mouthfeel: How Texture Makes Taste (New York City, NY: Columbia University Press), p. 100.

42. Mouritsen and Styrbæk.

43. Sharp et al.

44. Amanda K Ludlow et al. (2014), "Color Obsessions and Phobias in Autism Spectrum Disorders: The Case of J.G.," Neurocase, 20(3): 296-306.

45. Amanda K Ludlow and Arnold J Wilkins (2009), "Case Report: Color as a Therapeutic Intervention," Journal of Autism and Developmental Disorders, 39(5): 815-18.

46. Ludlow and Wilkins.

47. Jake Wallis Simons (2013), "Why Johnny Depp and I See the World through BlueTinted Spectacles," The Telegraph, September 29.

48. American Academy of Pediatrics (2009), "Learning Disabilities, Dyslexia, and Vision," Pediatrics, 124(2): 837-44. 
49. The Telegraph (2009), "The Latest Dieting Aid: Blue Tinted Spectacles," The Telegraph, May 25.

50. Charles Spence (2018), "What Is so Unappealing about Blue Food and Drink?," International Journal of Gastronomy and Food Science, 14: 1-8.

51. Christine Call, B Timothy Walsh, and Evelyn Attia (2013), "From DSM-IV to DSM-5: Changes to Eating Disorder Diagnoses," Current Opinion in Psychiatry, 26(6): 532-36.

52. Jennifer J Thomas et al. (2017), "Avoidant/Restrictive Food Intake Disorder: A ThreeDimensional Model of Neurobiology with Implications for Etiology and Treatment," Current Psychiatry Reports, 19(8): 54.

53. Thomas et al.

54. Mattias Strand, Yvonne von Hausswolff-Juhlin, and Elisabeth Welch (2019), "A Systematic Scoping Review of Diagnostic Validity in Avoidant/Restrictive Food Intake Disorder," International Journal of Eating Disorders, 52(4): 331-60.

55. Jane Wheatley (1973), "Putting Colour into Marketing," Marketing 67: 24-29.

56. Spence (2018).

57. Nobuyuki Sakai (2011), "Tasting with Eyes," I-Perception 2(8): 945.

58. Nick Rose (2015), "This Mad Scientist From Japan Has Created Neon-Coloured Udon," Vice, https://www.vice.com/en_us/article/wn77ez/this-mad-scientist-from-japan-hascreated-neon-coloured-udon.

59. Gray Chapman (2018), "The World's First Glow-in-the-Dark Ramen Pop-up Is Debuting in Atlanta," Atlanta Magazine, https://www.atlantamagazine.com/dining-news/worldsfirst-glow-dark-ramen-pop-up-debuting-atlanta/.

60. Spence (2018)

61. Arthur Zajonc (1993), Catching the Light: The Entwined History of Light and Mind (Oxford: Oxford University Press).

62. Andrew J Elliot and Markus A Maier (2014), "Color Psychology: Effects of Perceiving Color on Psychological Functioning in Humans," Annual Review of Psychology, 65(1): 95-120.

63. Anton J de Craen et al. (1996), "Effect of Colour of Drugs: Systematic Review of Perceived Effect of Drugs and of Their Effectiveness," BMJ, 313: 1624-6.

64. Stephen E Palmer, Karen B Schloss, and Jonathan Sammartino (2013), "Visual Aesthetics and Human Preference," Annual Review of Psychology, 64(1): 77-107.

65. Stephen E Palmer and Karen B Schloss (2010), "An Ecological Valence Theory of Human Color Preference," Proceedings of the National Academy of Sciences, 107(19): 8877-82.

66. Palmer, Schloss, and Sammartino

67. Joseph A Maga (1974), "Influence of Color on Taste Thresholds," Chemical Senses and Flavor, 1(1): 115-9.

68. Xiaoang Wan et al. (2014), "Cross-Cultural Differences in Crossmodal Correspondences between Basic Tastes and Visual Features," Frontiers in Psychology, 5: 1365.

69. Wendy V Parr, K Geoffrey White, and David A Heatherbell (2003), "The Nose Knows: Influence of Colour on Perception of Wine Aroma," Journal of Wine Research, 14(2-3): 79-101.

70. Qian Janice Wang and Charles Spence (2019), "Drinking through Rosé-Coloured Glasses: Influence of Wine Colour on the Perception of Aroma and Flavour in Wine Experts and Novices," Food Research International 126: 108678.

71. Charles Spence (2015), "On the Psychological Impact of Food Colour," Flavour, 4(1): 21.

72. Spence (2016)

73. Wan et al.

74. Michael Y Park, 2016, "What Even Is Blue Raspberry Anyway?," Bon Appétit, 2016 https://www.bonappetit.com/entertaining-style/pop-culture/article/what-is-blueraspberry-flavor.

75. Spence (2015)

76. Eloisa Steen and Tracey D Wade (2018), "Treatment of Co-Occurring Food Avoidance and Alcohol Use Disorder in an Adult: Possible Avoidant Restrictive Food Intake Disorder?" International Journal of Eating Disorders, 51(4):373-7.

77. Jennifer J Thomas and Kamryn T Eddy (2019), Cognitive-Behavioral Therapy for Avoidant/Restrictive Food Intake Disorder: Children, Adolescents, and Adults (Cambridge, UK: Cambridge University Press), p. 15.

78. Maria Rodale (2012), "The 'Nothing White' Diet," Huffington Post, https://www. huffpost.com/entry/the-nothing-white-diet_b_1183081.

79. Kathleen M Zelman (2010), "The Truth About White Foods: Should You Give up White Foods and Their 'Bad Carbs'?," WebMD, https://www.webmd.com/diet/obesity/ features/truth-about-white-foods.

80. Spence and Piqueras-Fiszman.

81. Lisa Niven-Phillips (2014), "Think Pink," Vogue, vogue.co.uk/article/think-pink-yslbeauty-rose-gold-touche-eclat.

82. Spence and Piqueras-Fiszman.

83. Fung.
84. Charles Spence (2020), "Black, White, and Clear: On the Semantic and Symbolic Meanings Associated with the Absence of Color in Food," in Amuse-Bouche: The Taste of Art, ed. Museum Tinguely Basel (Berlin, GER: Hatje Cantz), 30-39.

85. Bee Wilson (2008), Swindled: The Dark History of Food Fraud, from Poisoned Candy to Counterfeit Coffee (Princeton, NJ: Princeton University Press), p. 153.

86. Wilson.

87. Reay Tannahill (1988), Food in History (New York City, NY: Three Rivers Press).

88. Fung; Richardson.

89. Dan Piepenbring (2016), "How to Live Like a Musician: Eat Only White Foods," The Paris Review, https://www.theparisreview.org/blog/2016/05/17/the-musicians-day/.

90. Joris-Karl Huysmans (2003), Against Nature (A Rebours) (London, UK: Penguin Group), p. 13.

91. Andrea Goulet (2013), "Chapter 5 - Neurosyphilitics and Madmen: The French Finde-Siècle Fictions of Huysmans, Lermina, and Maupassant," in Literature, Neurology, and Neuroscience: Neurological and Psychiatric Disorders, ed. Stanley Finger, François Boller, and Anne Stiles (Amsterdam, NL: Elsevier), 73-91.

92. Patrick McGuinness (2003), "Introduction," in Against Nature (A Rebours) (London, UK: Penguin Group), xiii-xxxvi, p. xxix.

93. Elif Batuman (2017), The Idiot (New York, NY: Penguin Press), p. 37.

94. Anna Lavis (2017), "Food Porn, Pro-Anorexia and the Viscerality of Virtual Affect: Exploring Eating in Cyberspace," Geoforum, 84: 198-205; Charles Spence et al. (2016), "Eating with Our Eyes: From Visual Hunger to Digital Satiation," Brain and Cognition, 110: 53-63.

95. Silke-Maria Weineck (2006), "Digesting the Nineteenth Century: Nietzsche and the Stomach of Modernity," Romanticism, 12(1): 35-43, p. 40.

96. Peter Toohey (2012), Boredom: A Lively History (New Haven, CT: Yale University Press), p. 5.

\section{BIBLIOGRAPHY}

American Academy of Pediatrics. "Joint statement-Learning disabilities, dyslexia, and vision." Pediatrics 124, no. 2 (2009): 837-44.

Arnold, L Eugene, Nicholas Lofthouse, and Elizabeth Hurt. "Artificial food colors and attention-deficit/hyperactivity symptoms: conclusions to dye for." Neurotherapeutics 9 , no. 3 (2012): 599-609.

Bakroon, Asmaa, and Vasudevan Lakshminarayanan. "Visual function in autism spectrum disorders: a critical review." Clinical and Experimental Optometry 99, no. 4 (2016): 297-308.

Batuman, Elif. The Idiot. New York, NY: Pengu, 2017

Bell, Rudolph M. Holy Anorexia. Chicago, IL: University of Chicago Press, 1987.

Brown, Callie L, Emily B Vander Schaaf, Gail M Cohen, Megan B Irby, and Joseph A Skelton. "Association of Picky eating and food Neophobia with weight: a systematic review." Childhood Obesity 12, no. 4 (2016), no. : 247-62.

Brumberg, Joan Jacobs. Fasting Girls: The Emergence of Anorexia Nervosa as a Modern Disease. Cambridge, MA: Harvard University Press, 1988.

Call, Christine, B Timothy Walsh, and Evelyn Attia. "From DSM-IV to DSM-5: changes to eating disorder diagnoses." Current Opinion in Psychiatry 26, no. 6 (2013): 532-6.

Chapman, Gray. "The World's First Glow-in-the-Dark Ramen Pop-up Is Debuting in Atlanta. Atlanta Magazine.", 2018. https://www.atlantamagazine.com/dining-news/ worlds-first-glow-dark-ramen-pop-up-debuting-atlanta/.

Christensen, Stephanie Stensbjerg, Mette Bentz, Lars Clemmensen, Katrine StrandbergLarsen, and Else Marie Olsen. "Disordered eating behaviours and autistic traits-Are there any associations in nonclinical populations? A systematic review." European Eating Disorders Review 27, no. 1 (2019): 8-23.

Cornish, Elizabeth.. "A balanced approach towards healthy eating in autism." Journal of Human Nutrition and Dietetics 11, no. 6 (1998): 501-9.

Curwen, Caroline. "Music-colour synaesthesia: concept, context and qualia." Consciousness and Cognition 61 (2018): 94-106.

de Craen, Anton J, Pieter J Roos, A Leonard de Vries, J KleijnenEffect of colour of drugs: systematic review of perceived effect of drugs and of their effectiveness." BMJ 313 , no. 7072, (1996): 1624-6.

Dominick, Kelli C, Naomi Ornstein Davis, Janet Lainhart, Helen Tager-Flusberg, and Susan Folstein. "Atypical behaviors in children with autism and children with a history of language impairment." Research in Developmental Disabilities 28, no. 2 (2007): $145-62$.

Elliot, Andrew J, and Markus A Maier. "Color psychology: effects of perceiving color on psychological functioning in humans." Annual Review of Psychology 65 (2014): 95-120.

Elwin, Marie, Lena Ek, Lars Kjellin, and Agneta Schröder. "Too much or too little: hyperand hypo-reactivity in high-functioning autism spectrum conditions." Journal of Intellectual \& Developmental Disability 38, no. 3 (2013): 232-41.

Fung, Catherine H M. "Asperger's and musical creativity: the case of Erik Satie." Personality and Individual Differences 46, no. 8 (2009): 775-83.

Goulet, Andrea. "Chapter 5 - Neurosyphilitics and Madmen: The French Fin-de-Siècle Fictions of Huysmans, Lermina, and Maupassant." In Literature, Neurology, and 
Neuroscience: Neurological and Psychiatric Disorders, edited byStanley Finger, François Boller, and Anne Stiles, 73-91. Amsterdam, NL: Elsevier, 2013.

Grandgeorge, Marine, and Nobuo Masataka. "Atypical color preference in children with autism spectrum disorder." Frontiers in psychology 7, no. 2016 (2016), 1976.

Gunderman, Richard. "The Extraordinary Life of Nikola Tesla. Smithsonian Magazine.", 2018. https://www.smithsonianmag.com/innovation/extraordinary-life-nikola-tesla$180967758 /$.

Hafstad, Gertrud Sofie, Tilmann von Soest, and Leila Torgersen. "Early childhood precursors for eating problems in adolescence: a 15-year longitudinal community study." Journal of Eating Disorders 1 (2013): 35

Harrison, John. Synaesthesia: The Strangest Thing. Oxford, UK: Oxford University Press, 2001.

Hubbard, Kristie L, Sarah E Anderson, Carol Curtin, Aviva Must, and Linda G Bandini. "A comparison of food refusal related to characteristics of food in children with autism spectrum disorder and typically developing children." Journal of the Academy of Nutrition and Dietetics 114, no. 12 (2014): 1981-7.

Huysmans, Joris-Karl. Against Nature (A Rebours). London, UK: Penguin Group, 2003.

Jacobi, Corinna, Gabriele Schmitz, and W Stewart Agras. "Is picky eating an eating disorder?" International Journal of Eating Disorders 41, no. 7 (2008): 626-34.

Jamison, Kay Redfield. Touched with Fire: Manic-Depressive Illness and the Artistic Temperament. New York, NY: Free Press, 1993.

Jewanski, Jörg, Julia Simner, Sean A Day, Nicolas Rothen, and Jamie Ward. "The 'Golden Age' of Synesthesia Inquiry in the Late Nineteenth Century (1876-1895)." Journal of the History of the Neurosciences (2019): 1-28.

Johnson, Cynthia R, Benjamin L Handen, Meg Mayer-Costa, and Kelley Sacco. "Eating habits and dietary status in young children with autism." Journal of Developmental and Physical Disabilities 20, no. 5 (2008): 437-48.

Kanner, Leo. "Autistic disturbances of affective contact." Nervous Child (1943): 217-50.

Kirmayer, Laurence J, and Robert Lemelson, Constance A Cummings. Re-Visioning Psychiatry: Cultural Phenomenology, Critical Neuroscience, and Global Mental Health. Cambridge, UK: Cambridge University Press, 2015.

Kotler, L A, P Cohen, M Davies, D S Pine, B T Walsh, Patricia Cohen, Daniel S Pine, and B Timothy Walsh. "Longitudinal relationships between childhood, adolescent, and adult eating disorders." Journal of the American Academy of Child \& Adolescent Psychiatry 40, no. 12 (2001): 1434-40.

Lavis, Anna. "Food porn, pro-anorexia and the viscerality of virtual affect: exploring eating in cyberspace." Geoforum 84 (2017): 198-205.

Lemcke, Sanne, Erik T Parner, Merete Bjerrum, Per H Thomsen, and Marlene B Lauritsen. "Early regulation in children who are later diagnosed with autism spectrum disorder. A longitudinal study within the Danish national birth cohort." Infant Mental Health Journal 39, no. 2 (2018): 170-82.

Lockner, Donna W, Terry K Crowe, and Betty I Skipper. "Dietary intake and parents' perception of mealtime behaviors in preschool-age children with autism spectrum disorder and in typically developing children." Journal of the American Dietetic Association 108, no. 8 (2008): 1360-3.

Ludlow, Amanda K, and Arnold J Wilkins. "Case report: color as a therapeutic intervention." Journal of Autism and Developmental Disorders 39, no. 5 (2009): $815-8$.

Ludlow, Amanda K, Pamela Heaton, Elisabeth Hill, and Anna Franklin. "Color obsessions and phobias in autism spectrum disorders: the case of J.G." Neurocase 20, no. 3 (2014): 296-306.

Maga, Joseph A. "Influence of color on taste thresholds." Chemical Senses 1, no. 1 (1974): $115-9$.

Mascola, Anthony J, Susan W Bryson, and W Stewart Agras. "Picky eating during childhood: a longitudinal study to age 11 years." Eating Behaviors 11, no. 4 (2010): 253-7.

McGuinness, Patrick. "Introduction." In Against Nature, edited byA Rebours, xiii-xxxvi. London, UK: Penguin Group, 2003.

Moore, Charlotte. George and Sam: Autism in the Family. London, UK: Viking Penguin, 2004.

Mouritsen, Ole G, and Klavs Styrbæk. Mouthfeel: How Texture Makes Taste. New York City, NY: Columbia University Press, 2017.

Nadon, Geneviève, Debbie Ehrmann Feldman, Winnie Dunn, and Erika Gisel. "Mealtime problems in children with autism spectrum disorder and their typically developing siblings: a comparison study." Autism 15, no. 1 (2011): 98-113.

Nasser, Mervat., Melanie A Katzman, and Richard A Gordon. Eating Disorders and Cultures in Transition. Hove, UK: Brunner-Routledge, 2001

Niven-Phillips, Lisa. "Think Pink. Vogue.", 2014. vogue.co.uk/article/think-pink-ysl-beautyrose-gold-touche-eclat.

Palmer, Stephen E, and Karen B Schloss. "An ecological valence theory of human color preference." Proceedings of the National Academy of Sciences 107, no. 19 (2010): 8877-82.

Palmer, Stephen E, Karen B Schloss, and Jonathan Sammartino. "Visual aesthetics and human preference." Annual Review of Psychology 64 (2013): 77-107.

Park, Michael Y. "What Even Is Blue Raspberry Anyway?" Bon Appétit.", 2016. https:// www.bonappetit.com/entertaining-style/pop-culture/article/what-is-blue-raspberryflavor.
Parr, Wendy V, KGeoffrey White, and David A Heatherbell. "The nose knows: influence of colour on perception of wine aroma." Journal of Wine Research 14, no. 2-3 (2003): 79-101.

Piepenbring, Dan. "How to Live Like a Musician: Eat Only White Foods." The Paris Review.", 2016. https://www.theparisreview.org/blog/2016/05/17/the-musiciansday/.

Prescott, John. Taste Matters: Why We Like the Foods We Do. London, UK: Reaktion Books, 2012.

Richardson, Nick. "Velvet Gentleman. [Review of the Book A Mammal's Notebook: The Writings of Erik Satie.]." London Review of Books, vol. 37, 26-8, 2015.

Rodale, Maria. "The 'Nothing White' Diet." Huffington Post.", 2012. https://www.huffpost. com/entry/the-nothing-white-diet_b_1183081.

Rose, Nick. "This Mad Scientist From Japan Has Created Neon-Coloured Udon." Vice.", 2015. https://www.vice.com/en_us/article/wn77ez/this-mad-scientist-from-japan-hascreated-neon-coloured-udon.

Sakai, Nobuyuki. "Tasting with eyes." I-Perception 2 (2011), 945.

Schreck, Kimberly A, Keith Williams, and Angela F Smith. "A comparison of eating behaviors between children with and without autism." Journal of Autism and Developmental Disorders 34, no. 4 (2004): 433-8.

Sharp, William G, Rashelle C Berry, Courtney McCracken, Nadrat N Nuhu, Elizabeth Marvel, Celine A Saulnier, Ami Klin, Warren Jones, and David L Jaquess. "Feeding problems and nutrient intake in children with autism spectrum disorders: a meta-analysis and comprehensive review of the literature." Journal of Autism and Developmental Disorders 43, no. 9 (2013): 2159-73.

Spence, Charles. "On the psychological impact of food colour." Flavour 4, no. 1 (2015): 21. . "What is so unappealing about blue food and drink?" International Journal of Gastronomy and Food Science 14 (2018): 1-8.

. "The Psychological Effects of Food Colors." In Handbook on Natural Pigments in Food and Beverages, edited byReinhold Carle, and RalfM Schweiggert, 29-58. Duxford, UK: Woodhead Publishing, 2016.

_. "Black, White, and Clear: On the Semantic and Symbolic Meanings Associated with the Absence of Color in Food." Amuse-Bouche: The Taste of Art, 30-9. Berlin, GER: Museum Tinguely Basel, Hatje Cantz, 2020.

Spence, Charles, Katsunori Okajima, Adrian David Cheok, Olivia Petit, and Charles Michel. "Eating with our eyes: from visual hunger to digital satiation." Brain and Cognition 110 (2016): 53-63.

Simons, Jake Wallis. "Why Johnny Depp and I see the world through blue-tinted spectacles." The Telegraph (2013).

Spence, Charles, and Betina Piqueras-Fiszman. The Perfect Meal: The Multisensory Science of Food and Dining. Oxford, UK: Wiley Blackwell, 2014.

Steen, Eloisa, and Tracey D Wade. "Treatment of co-occurring food avoidance and alcohol use disorder in an adult: possible avoidant restrictive food intake disorder?" International Journal of Eating Disorders 51, no. 4 (2018): 373-7.

Strand, Mattias, Yvonne von Hausswolff-Juhlin, and Elisabeth Welch. "A systematic scoping review of diagnostic validity in avoidant/restrictive food intake disorder." International Journal of Eating Disorders 52, no. 4 (2019): 331-60.

Tallis, Raymond. Hunger. Stocksfield. UK: Acumen Publishing, 2008.

Tannahill, Reay. Food in History. New York City, NY: Three Rivers Press, 1988.

The Telegraph. "The latest dieting aid: blue tinted spectacles." The Telegraph (2009).

Thomas, Jennifer J, Elizabeth A Lawson, Nadia Micali, Madhusmita Misra, Thilo Deckersbach, and Kamryn T Eddy. "Avoidant/Restrictive food intake disorder: a threedimensional model of neurobiology with implications for etiology and treatment." Current Psychiatry Reports 19, no. 8 (2017), 54.

Thomas, Jennifer J, and Kamryn T Eddy. Cognitive-behavioral therapy for avoidant/ restrictive food intake disorder: children, adolescents, and adults. Cambridge, UK: Cambridge University Press, 2019.

Toohey, Peter. Boredom: A Lively History. New Haven, CT: Yale University Press, 2012.

Triarhou, Lazaros C. "Neuromusicology or Musiconeurology? "Omni-art" in Alexander Scriabin as a fount of ideas." Frontiers in Psychology 7 (2016), 364.

Volta, Ornella. A Mammal's Notebook: The Writings of Erik Satie. London, UK: Atlas Press, 1996.

Wan, Xiaoang, Andy T Woods, Jasper J F van den Bosch, Kirsten J McKenzie, Carlos Velasco, and Charles Spence. "Cross-cultural differences in crossmodal correspondences between basic tastes and visual features." Frontiers in Psychology 5 (2014), 1365.

Wang, Qian Janice, and Charles Spence. "Drinking through rosé-coloured glasses: influence of wine colour on the perception of aroma and flavour in wine experts and novices." Food Research International 126 (2019): 108678.

Ward, Jamie. "Synesthesia." Annual Review of Psychology 64 (2013): 49-75.

Weineck, Silke-Maria. "Digesting the nineteenth century: Nietzsche and the stomach of modernity." Romanticism 12, no. 1 (2006): 35-43.

Wheatley, Jane. "Putting colour into marketing." Marketing 67 (1973): 24-9.

Wilson, Bee. Swindled: The Dark History of Food Fraud, from Poisoned Candy to Counterfeit Coffee. Princeton University Press: Princeton, NJ, 2008.

Zajonc, Arthur. Catching the Light: The Entwined History of Light and Mind. Oxford University Press: Oxford, 1993.

Zelman, Kathleen M. "The Truth About White Foods: Should You Give up White Foods and Their 'Bad Carbs'? WebMD.", 2010. https://www.webmd.com/diet/obesity/features/ truth-about-white-foods. 